\title{
Comment on a meta-analysis comparing hepatic resection or transarterial chemoembolization as initial treatment for hepatocellular carcinoma
}

This article was published in the following Dove Press journal:

Drug Design, Development and Therapy

13 October 2015

Number of times this article has been viewed

\author{
Jian-Hong Zhong ${ }^{1,2}$ \\ Bang-De Xiang ${ }^{1,2}$ \\ Le-Qun $\mathrm{Li}^{1,2}$
}

'Hepatobiliary Surgery Department, Affiliated Tumor Hospital of Guangxi Medical University, Nanning, People's Republic of China; ${ }^{2}$ Guangxi Liver Cancer Diagnosis and Treatment Engineering and Technology Research Center, Nanning, People's Republic of China
Correspondence: Le-Qun Li Hepatobiliary Surgery Department, Affiliated Tumor Hospital of Guangxi Medical University, He Di Rd \#7I, Nanning 53002I, People's Republic of China

Tel +86 77I 5330855

Fax $+8677 \mid 5312000$

Email xitongpingjia@I63.com

\section{Dear editor}

We read with great interest the meta-analysis by Tian et al ${ }^{1}$ comparing the efficacy of initial hepatic resection (HR) or transarterial chemoembolization (TACE) for patients with primary hepatocellular carcinoma (HCC). The results from this analysis of eleven cohort studies involving 6,297 patients suggested similar overall survival (OS) and recurrence rate for the two techniques. We believe this conclusion should be treated with caution because it conflicts with much larger original studies ${ }^{2,3}$ and large systematic reviews. ${ }^{4,5}$

Potential problems with patient heterogeneity weaken the validity of the metaanalysis by Tian et al. Those authors did not mention explicitly that they selected only studies examining HR or TACE as initial therapy, yet all except one study focused on initial therapy. That one study, ${ }^{6}$ involving 1,296 patients, compared preoperative TACE plus HR with HR alone. This may have introduced significant clinical heterogeneity into the study population, since preoperative TACE plus HR, HR alone, and TACE alone are associated with substantially different OS. In addition, this meta-analysis included patients with early, ${ }^{7}$ intermediate, ${ }^{8,9}$ and advanced HCC. ${ }^{10}$ This may have introduced additional heterogeneity, since recommended $\mathrm{HCC}$ treatments depend on tumor stage. ${ }^{11}$ Unfortunately, it is impossible to assess tumor stage in this meta-analysis because essential information, including tumor number and incidence of macrovascular invasion, is not reported.

For reasons that are unclear, this meta-analysis failed to include several studies comparing initial HR and TACE to treat primary HCC. These include large, propensity score-matched studies; ${ }^{2,12}$ a large, well-designed retrospective study; ${ }^{13}$ and a randomized trial. ${ }^{14}$ All four of these studies reported that initial HR was associated with significantly longer short- and long-term OS in patients with intermediate or advanced HCC. A meta-analysis ${ }^{15}$ with similar goals to Tian et al but much larger - bringing together 50 studies involving 14,673 patients with primary $\mathrm{HCC}$ - found significantly higher 1-, 3-, and 5-year OS after initial HR than initial TACE. Subgroup analyses in that study showed similar results for patients in Barcelona Clinic Liver Cancer (BCLC) stage A, patients in BCLC stage B, and patients with portal vein tumor thrombus.

Several methodological issues in the meta-analysis by Tian et al further weaken their conclusions. First, although those authors did acknowledge that HR is considered curative while TACE is only palliative, they nevertheless calculated a recurrence rate for TACE and compared it with recurrence after HR. This may not be valid, since it 
is unclear whether tumors completely disappear after one or more cycles of TACE. Second, although most studies in this meta-analysis were "high quality" based on the NewcastleOttawa Scale, all were low quality based on Cochrane quality assessment standards. Third, those authors did not report intention-to-treat analyses, which meant, among other things, that the same total number of patients in each study was used to calculate survival at $1,2,3,4$, and 5 years. The reality is that patients die during follow-up, which intention-to-treat analysis would capture. Fourth, $I^{2}$ in most studies in the meta-analysis was $>80 \%$, indicating significant heterogeneity and suggesting that meta-analysis may be inappropriate.

Though we compliment Tian et al on their effort, and studies like this meta-analysis are necessary to gain a definitive picture of optimal initial treatment, which remains controversial for certain types of HCC patients, ${ }^{11,16}$ such studies should be conducted in a way that controls for patient heterogeneity.

\section{Disclosure}

The authors report no conflicts of interest in this communication.

\section{References}

1. Tian X, Dai Y, Wang DQ, et al. Transarterial chemoembolization versus hepatic resection in hepatocellular carcinoma treatment: a meta-analysis. Drug Des Devel Ther. 2015;9:4431-4440.

2. Zhong JH, Ke Y, Gong WF, et al. Hepatic resection associated with good survival for selected patients with intermediate and advanced-stage hepatocellular carcinoma. Ann Surg. 2014;260(2): 329-340.

3. Torzilli G, Belghiti J, Kokudo N, et al. A snapshot of the effective indications and results of surgery for hepatocellular carcinoma in tertiary referral centers: is it adherent to the EASL/AASLD recommendations?: an observational study of the HCC East-West study group. Ann Surg. 2013;257(5):929-937.

4. Zhong JH, Ke Y, Wang YY, Li LQ. Liver resection for patients with hepatocellular carcinoma and macrovascular invasion, multiple tumours, or portal hypertension. Gut. 2015;64(3):520-521.
5. Zhong JH, Rodríguez AC, Ke Y, Wang YY, Wang L, Li LQ. Hepatic resection as a safe and effective treatment for hepatocellular carcinoma involving a single large tumor, multiple tumors, or macrovascular invasion. Medicine (Baltimore). 2015;94(3):e396.

6. Shi HY, Wang SN, Wang SC, Chuang SC, Chen CM, Lee KT. Preoperative transarterial chemoembolization and resection for hepatocellular carcinoma: a nationwide Taiwan database analysis of long-term outcome predictors. J Surg Oncol. 2014;109(5):487-493.

7. Hsu KF, Chu CH, Chan DC, et al. Superselective transarterial chemoembolization vs hepatic resection for resectable early-stage hepatocellular carcinoma in patients with Child-Pugh class a liver function. Eur J Radiol. 2012;81(3):466-471.

8. Luo J, Peng ZW, Guo RP, et al. Hepatic resection versus transarterial lipiodol chemoembolization as the initial treatment for large, multiple, and resectable hepatocellular carcinomas: a prospective nonrandomized analysis. Radiology. 2011;259(1):286-295.

9. Lin CT, Hsu KF, Chen TW, et al. Comparing hepatic resection and transarterial chemoembolization for Barcelona Clinic Liver Cancer (BCLC) stage B hepatocellular carcinoma: change for treatment of choice? World J Surg. 2010;34(9):2155-2161.

10. Liu PH, Lee YH, Hsia CY, et al. Surgical resection versus transarterial chemoembolization for hepatocellular carcinoma with portal vein tumor thrombosis: a propensity score analysis. Ann Surg Oncol. 2014;21(6):1825-1833.

11. European Association For The Study Of The Liver; European Organisation For Research And Treatment Of Cancer. EASL-EORTC clinical practice guidelines: management of hepatocellular carcinoma. J Hepatol. 2012;56(4):908-943.

12. Hsu CY, Hsia CY, Huang YH, et al. Comparison of surgical resection and transarterial chemoembolization for hepatocellular carcinoma beyond the Milan criteria: a propensity score analysis. Ann Surg Oncol. 2012;19(3):842-849.

13. Peng ZW, Guo RP, Zhang YJ, Lin XJ, Chen MS, Lau WY. Hepatic resection versus transcatheter arterial chemoembolization for the treatment of hepatocellular carcinoma with portal vein tumor thrombus. Cancer. 2012;118(19):4725-4736.

14. Yin L, Li H, Li AJ, et al. Partial hepatectomy vs. transcatheter arterial chemoembolization for resectable multiple hepatocellular carcinoma beyond Milan Criteria: a RCT. J Hepatol. 2014;61(1):82-88.

15. Qi X, Wang D, Su C, Li H, Guo X. Hepatic resection versus transarterial chemoembolization for the initial treatment of hepatocellular carcinoma: a systematic review and meta-analysis. Oncotarget. 2015;6(21):18715-18733.

16. Zhong JH, You XM, Lu SD, et al. Historical comparison of overall survival after hepatic resection for patients with large and/or multinodular hepatocellular carcinoma. Medicine (Baltimore). 2015;94(35):e1426.

Dove Medical Press encourages responsible, free and frank academic debate. The content of the Drug Design, Development and Therapy 'letters to the editor' section does not necessarily represent the views of Dove Medical Press, its officers, agents, employees, related entities or the Drug Design, Development and Therapy editors. While all reasonable steps have been taken to confirm the content of each letter, Dove Medical Press accepts no liability in respect of the content of any letter, nor is it responsible for the content and accuracy of any letter to the editor.

\section{Publish your work in this journal}

Drug Design, Development and Therapy is an international, peerreviewed open-access journal that spans the spectrum of drug design and development through to clinical applications. Clinical outcomes, patient safety, and programs for the development and effective, safe, and sustained use of medicines are a feature of the journal, which has also been accepted for indexing on PubMed Central. The manuscript management system is completely online and includes a very quick and fair peer-review system, which is all easy to use. Visit http://www.dovepress.com/testimonials.php to read real quotes from published authors. 